\title{
Integrating models of self-regulation
}

\author{
Michael Inzlicht, Kaitlyn M. Werner \\ University of Toronto
}

\author{
Julia L. Briskin, Brent W. Roberts \\ University of Illinois at Urbana Champaign
}

\begin{abstract}
Self-regulation is a core aspect of human functioning that helps facilitate the successful pursuit of personal goals. There has been a proliferation of theories and models describing different aspects of self-regulation both within and outside of psychology. All of these models provide insights about selfregulation, but sometimes talk past each other, make only shallow contributions, or make contributions that are under-appreciated by scholars working in adjacent areas. The purpose of this article is to integrate across the many different models in order to refine the vast literature on selfregulation. To achieve this objective, we first review some of the more prominent models of selfregulation coming from social psychology, personality psychology, and cognitive neuroscience. We then integrate across these models based on four key elements-level of analysis, conflict, emotion, and cognitive functioning - specifically identifying points of convergence, but also points of insufficient emphasis. We close with prescriptions for future research.
\end{abstract}

Keywords: self-regulation, self-control, goal pursuit, cognitive control, effort, personality, cognitive ability

\section{In Press at Annual Review of Psychology}

Please cite this paper as: Inzlicht, M., Werner, K. M., Briskin, J. L., \& Roberts, B. W. (in-press). Integrating models of self-regulation. Annual Review of Psychology.

Self-regulation is a boon to the well-functioning person, if not a well-functioning society. With connections between self-regulation and outcomes as disparate as health, longevity, criminality, financial savings, job performance, and relationship satisfaction (to name but a few), it is no wonder the lay public and scholars alike are keen to understand and cultivate it (Baumeister, Heatherton, \& Tice, 1994; Moffitt et al., 2011). Despite this interest (or perhaps because of it), progress in understanding self-regulation has been hampered by too many models and theories, each describing self-regulation at different levels of analysis with not enough integration.

Some models, for example, focus entirely on goals (Kruglanski et al., 2002; Locke \& Latham, 2006), whereas others focus on the fragility of willpower (Baumeister, Vohs, \& Tice, 2007). Some models center on human personality and traits (Roberts, Lejuez, Krueger, Richards, \& Hill, 2014; Whiteside \& Lynam, 2001), whereas others focus on conflicts between goals and temptations (Hofmann, Friese, \& Strack, 2009). Still others construe self-regulation as dependent on a self-monitoring process (Carver \& Scheier, 1998),

Correspondence concerning this paper should be addressed to Michael Inzlicht, Department of Psychology, University of Toronto, 1265 Military

Trail, Toronto, ON, M1C 1A4, Canada.Email: michael.inzlicht@utoronto.ca whereas others construe it as a series of learnable strategies (Duckworth, Gendler, \& Gross, 2016). All of these models provide insights about self-regulation, but sometimes talk past each other, make only shallow contributions, or make contributions that are under-appreciated by scholars working in adjacent areas.

Here, we attempt to remedy this situation by integrating across different models of self-regulation coming from disparate research traditions in social psychology, personality psychology, and cognitive neuroscience. Such integration will not only allow us to identify where models converge, but also where there has been insufficient emphasis. Critically, highlighting how the various models fit together can clarify concepts that have proved perplexing because of the imprecise use of terminology. Perhaps the clearest example of such confusion is with the term self-regulation itself. We thus begin with a few definitions of overlapping terms.

\section{Distinguishing Between Self-Regulation, Self-Control, and Cognitive Control}

Although often used interchangeably (e.g., Vohs \& Baumeister, 2004), we suggest that self-regulation and self-control refer to distinct processes (Milyavskaya, Berkman, \& De Ridder, 2019), both of which resemble 


\begin{tabular}{|c|c|}
\hline Term & Definition \\
\hline Self-Regulation & $\begin{array}{l}\text { Dynamic process of determining desired end-point and then taking action to move toward it } \\
\text { while monitoring progress along the way. }\end{array}$ \\
\hline Self-Control & Process of advancing one goal over a second goal when the two come into conflict. \\
\hline Cognitive Control & $\begin{array}{l}\text { Flexible allocation of attention in the service of goal-directed behavior in the face of more } \\
\text { habitual or immediately compelling behaviors. }\end{array}$ \\
\hline Goal & Cognitive representation of a desired end state that a person is committed to attain. \\
\hline Conflict & $\begin{array}{l}\text { Discrepancy between goals that are simultaneously active, mutually exclusive, and compete for a } \\
\text { single response. }\end{array}$ \\
\hline Impulsivity & $\begin{array}{l}\text { Tendency to act on immediate urges, either before consideration of possible negative } \\
\text { consequences or despite consideration of likely negative consequences. }\end{array}$ \\
\hline Conscientiousness & $\begin{array}{l}\text { Propensity to follow socially prescribed norms for impulse control, to be goal directed, to plan, } \\
\text { and to delay gratification. }\end{array}$ \\
\hline
\end{tabular}

but are not isomorphic with cognitive control (Cohen, 2017). Self-regulation is a broad term that refers to the dynamic process of determining a desired end state (i.e., goal) and then taking action to move toward it while monitoring progress along the way (Carver \& Scheier, 1998). Self-regulation involves steering one's behavior toward a desired end state. End states (or goals) can be defined as specific desired behaviors (e.g., physical exercise), thoughts or attitudes (e.g., being compassionate), or emotional states (e.g., being content). Self-regulation, therefore, subsumes not only the regulation of behavior, but also of thoughts and emotions (e.g., Gross, 2015). Self-regulation can be thought of as an umbrella term that includes a wide of array goal-relevant activities, such as deciding which goal to pursue, planning how to pursue it, implementing these plans, shielding goals from competing concerns, and sometimes even abandoning goals (Fujita, 2011; Gollwitzer, 1999; Ludwig, Srivastava, \& Berkman, 2019; Shah, Friedman, \& Kruglanski, 2002; Wrosch, Scheier, Miller, Schulz, \& Carver, 2003). For example, setting a goal to jog at 6am is an act of self-regulation, as is planning to go to bed early the night before to avoid being tired, as is temporarily abandoning one's jogging goal when one is sick.

Self-regulation includes the various ways in which people modify their thoughts, feelings, and behaviors in the service of a personal goal, including engaging in effortful self-control. Self-control represents one form of self-regulation; but, not all forms of self-regulation entail self-control (Fujita, 2011). We define self-control as the process of resolving conflict (real or anticipated) between two competing goals. For example, when deciding between a delicious poutine and a healthy salad for lunch, self-control is recruited to resolve the conflict between the short-term goal of eating delicious food versus the long-term goal of being healthy and fit.

Self-control is often characterized as pertaining exclusively to resolving conflicts between goals that are temporally asymmetric, that is goals with small immediate rewards versus goals with larger yet delayed rewards (Ainsley, 1974; Duckworth, Gendler, et al., 2016; Fujita, 2011). Self-control, according to this view, is demonstrated when a person resists the desire for the small immediate reward in favor of the larger later reward. Here, however, we relax the assumption of temporal asymmetry and count as self-control the resolution of conflict between any two goals, be they goals that pit short- and long-term rewards (e.g., poutine vs. salad) or goals that pit two separate long-term rewards that compete for one's limited time (e.g., study for test vs. hang out with friends).

Self-control has typically been characterized by the effortful inhibition of impulses, including effortfully overriding unwanted thoughts, feelings, and behaviors (Baumeister, 2014). More recently, the concept of self-control has expanded to include any means to advance one motive over another (Fujita, 2011), including means that do and do not involve effort (Galla \& Duckworth, 2015; Gillebaart \& de Ridder, 2015; Hennecke, Czikmantori, \& Brandstätter, 2019), means that involve inhibiting something undesired or enacting something desired (De Ridder, De Boer, Lugtig, Bakker, \& van Hooft, 2011; Gillebaart, 2018), 
or means that involve reactive inhibition or more proactive forms of resolving conflict (Duckworth, Gendler, et al., 2016; Fujita, 2011). Our definition of self-control, therefore, expands on prior definitions by including more varieties of goal conflicts and more varieties of means to resolve goal conflicts.

In sum, what differentiates self-control from self-regulation is the presence of conflict between motives (Fujita, 2011). Self-control refers to all means of resolving conflicts between competing goals (including, but not limited to inhibition), whereas self-regulation can be conflict-free and refers to the broader process of steering one's behavior toward a desired end state and includes setting goals, monitoring goal progress, and acting in accordance with goals (Carver \& Scheier, 1998; Gillebaart, 2018).

Stemming from cognitive neuroscience is the related concept of cognitive control or executive function. Cognitive control refers to the attentional processes that allow behavior to vary from moment to moment based on current goals rather than remaining rigid and inflexible; it is the flexible allocation of attention in the service of goal-directed behavior in the face of more habitual or immediately compelling behaviors (Cohen, 2017). This emphasis on modifying some aspect of the self in service of meeting a goal bears a striking similarity to the definition of self-regulation; in fact, self-regulation was long thought to rely on the more basic attentional components of cognitive control (Hofmann, Schmeichel, \& Baddeley, 2012). More recently, however, scholars have come to question the reliance of self-regulation on cognitive control, mostly because measures of each construct are unrelated (Dang, King, \& Inzlicht, 2020; Eisenberg et al., 2019; Saunders, Milyavskaya, Etz, Randles, \& Inzlicht, 2018). Typically, the term cognitive control is used when describing the flexible use of low-level cognitive operations like attention and working memory, whereas self-regulation is used when discussing the flexible adjustment of behavior in the real world.

An influential account indicates that cognitive control consists of three distinct (yet related) factors of inhibition, attentional shifting, and working-memory updating (Miyake \& Friedman, 2012; Miyake et al., 2000; but see, Doebel, 2020). Despite its widespread appeal, however, there is growing sense that cognitive control (or executive function) might be indistinguishable from general intelligence or the broad abilities (e.g., processing speed, memory) that comprise general intelligence (Conway, Kane, \& Engle, 2003; Engelhardt et al., 2016; Jewsbury,
Bowden, \& Strauss, 2016). If cognitive control is indistinguishable from intelligence, even at the level of genetic overlap (Engelhardt et al., 2016), it should perhaps be treated independently from self-regulation, the so-called non-cognitive factors important for success (Duckworth et al., 2019).

\section{Models of Self-Regulation}

Much like there are many different perspectives and definitions of what constitutes self-regulation, so too are there various models that seek to explain various aspect(s) of the regulatory process. In this section, we provide a non-exhaustive list and summary of these models, focusing on ones that make general contributions to the process of self-regulation (cf. Neal, Ballard, \& Vancouver, 2017).

\section{Cybernetic Control}

Cybernetics is the science of control in animals and machines (Wiener, 1948). Perhaps the most influential general model of self-regulation (Carver \& Scheier, 1998), cybernetic control is based on simple feedback loops that contain four key elements: (1) a goal, set point, or standard; (2) input about the current state of the organism with regards to the set point; (3) a system that monitors for conflicts or discrepancies between the set point and the current state of the organism; and (4) a system that implements changes that reduce the discrepancy between current and desired states. Critically, each of these elements is connected to one another via a feedback loop (see Figure 1). The output of the implementing system feeds back to change the current state of the organism, after which the current state is again compared to the goal state by the monitoring system. This process is repeated until the size of the discrepancy between the goal state and the current state is reduced to some acceptable level.

For example, students struggling to get their homework done can set a goal to do their homework after dinner. Once dinner passes, they would evaluate whether their current behavior matches their goal (e.g., I am watching Netflix but I should do my homework); when a discrepancy is detected, they could implement a new behavioral course congruent with their goals (e.g., close the computer, open my books) and repeatedly monitor their behavior until the desired task is complete.

Cybernetic feedback principles are also at the heart of dominant models of control from cognitive neuroscience, which place special importance on 
neural systems responsible for monitoring conflicts between competing response tendencies (Botvinick, Braver, Barch, Carter, \& Cohen, 2001) or between predictions and outcomes (Alexander \& Brown, 2011; Holroyd \& Coles, 2002). Conflict monitoring theory, for example, focuses on how a monitoring system generated by the dorsal anterior cingulate cortex scrutinizes action tendencies for potential conflicts so that control mechanisms generated by the dorsolateral prefrontal cortex can override unwanted tendencies to promote effective goal pursuit. More recent computational models of cognitive control elaborate further on the precise function of these neural substrates, but one constant is that detecting and responding to conflict, discrepancies, or prediction errors appear critical (Shenhav, Botvinick, \& Cohen, 2013; Vassena, Holroyd, \& Alexander, 2017).

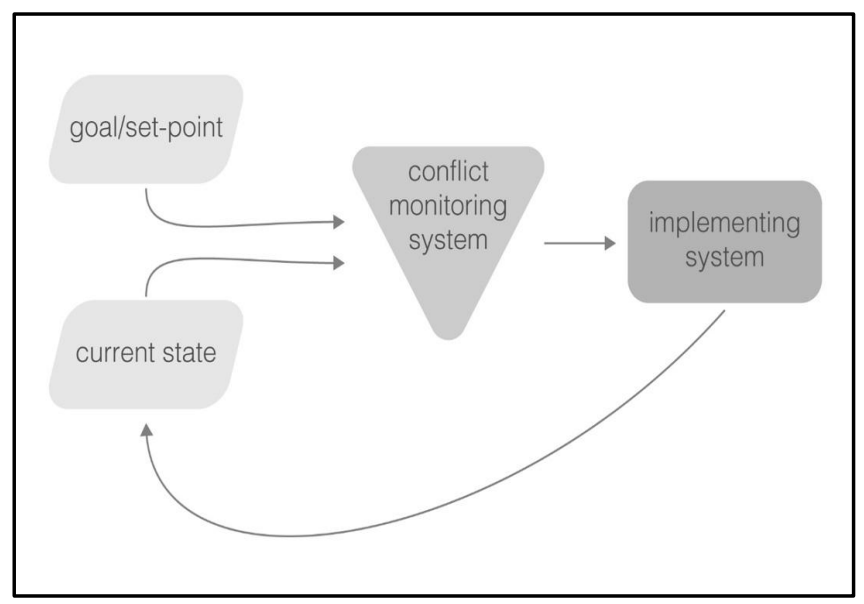

Figure 1. Cybernetic model of self-regulation

\section{Goal Systems Theory}

Another model focusing specifically on the goal concept is Goal Systems Theory (Kruglanski et al., 2002). Similar to the cybernetic model, goals are broadly defined as cognitive representations of desired end states; however, rather than focusing on feedback loops, this approach emphasizes how the structural organization of goals and the means by which they can be attained impact the process of self-regulation. Goals and their associated means (i.e., the different pathways by which people can attain their goal) make up a hierarchical interconnected network called a goal system, and the strength of the various goal-means associations is what ultimately drives behaviour. In other words, means that are more strongly associated with a specific goal are more likely to be selected than means that have a weaker connection.
The strength of connections within a goal network depends on the uniqueness and substitutability of a given means for that specific goal. That is, having many means attached to a particular goal dilutes the strength of each individual goal-means connection (therefore decreasing the likelihood of any particular means being selected), whereas goals with fewer, more unique means have stronger connections (therefore increasing the likelihood of behavioural enactment) (Kruglanski et al., 2002). For example, if a person has a very specific goal to attend an exercise class that they signed up for, there are limited means that can be used to enact this goal (i.e., the only viable option is to simply attend the class as planned). Because alternative means are not readily available, the strength of the association between the goal to attend an exercise class and the means of actually going to the scheduled class will be quite strong. By contrast, a less specific goal typically has many means associated with it. For the broader goal to be healthy, you could attend an exercise class, cook a healthy meal, meditate, make time to relax with friends, schedule a doctor's appointment, etc. Because there are so many equally viable options to enact this goal, the strength of the association between each individual means and the target goal gets diluted.

When a goal is considered particularly important, people select means that are most instrumental to (or most strongly and uniquely associated with) pursuing that goal; means that advance a single goal are called unifinal means. For example, if one has the goal of "having fun," and riding a roller coaster is the means most strongly and uniquely associated with this goal, one is likely to select this option. However, if one has additional goals to "having fun" that impose restrictions on the means available, riding a roller coaster is unlikely to be selected. For example, if one has the goal of "having fun," but also has the goal of "staying socially connected," a roller coaster may not be the best option to advance both goals. Instead, one may select a multifinal means (Köpetz, Faber, Fishbach, \& Kruglanski, 2011), or a means that advances multiple goals simultaneously. Instead, a person may choose the means of "playing a card game with a friend," which advances both the goal to have fun and being socially connected. Multifinal means satisfy multiple goals in one fell swoop, constituting greater "bang for the psychological buck" (Kruglanski et al., 2002, p. 358). 


\section{Dual Systems Models}

From Plato to Saint Augustine, from Descartes to Freud, as long as scholars have put pen to paper (or ink to parchment), they have described behaviour as being a product of two distinct mental operations. Indeed, dual systems models of self-regulation remain more popular than ever (Cohen, 2017; Heatherton \& Wagner, 2011; Hofmann et al., 2009; Kahneman, 2011; Metcalfe \& Mischel, 1999; Thaler \& Shefrin, 1981). While there are many flavors to these models, they all share the notion that two distinct systemsunimaginatively named System 1 and System IIregulate behavior.

First, there is System I, also known as the impulsive system, automatic system, hot system, reflexive system, or the doer. System I is a fast system that is responsive to the immediate environment, especially stimuli with high incentive value, for example stimuli we might describe as temptations. This system responds to stimuli that are temporally and spatially near, serves short-term gratifications, and produces behaviors that are rigid and habitual, most often an urge to approach and act on the temptation at hand (Hofmann et al., 2009). System I devalues stimuli that are temporally distant (Ainslie, 1974; Mischel, Ebbesen, \& Raskoff Zeiss, 1972) or that are contingent on effort (Apps, Grima, Manohar, \& Husain, 2015; Westbrook, Kester, \& Braver, 2013). This impulsive system is associated with activity in subcortical regions of the brain involved in reward and emotion, such as the nucleus accumbens in the ventral striatum, the amygdala, and the insula (Heatherton \& Wagner, 2011; Lopez, Hofmann, Wagner, Kelley, \& Heatherton, 2014).

Next, there is System II, also known as the control system, cold system, reflective system, or the planner. System II is a slow system that carefully and effortfully deliberates between possible response options and is responsible for higher-order mental operations, such as making deliberate judgments and evaluations, setting goals, and creating strategies for goal pursuit (Hofmann et al., 2009). Unlike System I, this system is influenced by long-term goals to flexibly respond to the environment, including overriding behavioral tendencies from the impulsive system. Also unlike System I, the control system processes stimuli sequentially, meaning that it is limited by a person's attentional capacity, which can fluctuate from moment to moment based on concurrent processing demands (Cowan, 2001). This control system is associated with regions of the lateral prefrontal cortex (Berkman, Falk, \& Lieberman, 2011; Heatherton \& Wagner, 2011).
Dual systems accounts suggest that behavior is jointly produced by these two independent systems that might be mutually supportive or might be in conflict. When the two systems are aligned, for example when the goal of driving home is supported by the urge not to crash into a snowbank, behavior is determined by an unconflicted self-regulatory process. Self-control dilemmas arise, however, when the two independent systems conflict, for example when a dieter is offered delicious yet unhealthy poutine. In such a dilemma, the behavioral option that is selected (e.g., eat poutine vs refusing it) is determined by a winner-takes-all competition between the two systems, with the more strongly activated and recruited system typically determining behavior (Hofmann et al., 2009). These self-control dilemmas, in other words, are conceived as a see-saw battle between the two opposing modes of processing where either the impulsive system is dominant or the control system overrides and inhibits the impulsive system so that it wins out (Lopez et al., 2017). Critically, the balance between the two opposing systems can be disrupted by various dispositional moderators, such as individual differences in impulsivity and restraint (Carver, 2005) or by situational moderators, such as fatigue, mood, stress, alcohol consumption, and brain damage (Heatherton \& Wagner, 2011).

Cognitive control is also described as a dual process model whereby an automatic (i.e., heavily trained) process is pitted against a controlled (i.e., flexible, yet effortful) process (Kool \& Botvinick, 2018; Shenhav, 2017). Attributes that distinguish automatic from controlled processes include speed of processing, flexibility, susceptibility to interference from other ongoing processes, and reliance on a central, limitedcapacity operator. The color-naming Stroop task highlights a number of these criteria: color-naming is slower than word-reading; reading interferes with color-naming, but color naming does not interfere with reading; and, color naming is interfered by other controlled processes, for example mental arithmetic (Cohen, 2017). A central question in this research tradition is what moves a person from default habitual processing to flexible yet costly controlled processing. The answer is typically some form of conflict, be that conflict between intended and actual responses (i.e., errors), between predicted and actual outcomes (i.e., prediction errors), or online processing conflict between different response options (Kool, Shenhav, \& Botvinick, 2017). 


\section{Choice Models}

In contrast to dual process models - which suggest that self-control consists of a battle between impulsive and deliberative processes, like metaphorical devils and angels on one's shoulders vying for dominancechoice models posit that self-control is nothing more than the behavioral enactment of some value-based choice (Berkman, Hutcherson, Livingston, Kahn, \& Inzlicht, 2017; Buckholtz, 2015; Neal et al., 2017). According to this view, control is the product of a single valuation process wherein various response options are assigned some subjective value and then a decision about which option to act upon is made through a dynamic integration of these competing values. Selfcontrol thus involves calculating a value for each option by integrating the benefits of each option minus their attendant costs and then enacting the most valued option (Berkman, Hutcherson, et al., 2017). Interestingly, the value ascribed to future (vs. present) outcomes appears especially critical for successful selfcontrol not just in the lab, but in the real world (Kronke et al., in press).

The calculation of option benefits is based on things like monetary incentives, social approval, proximity to core values, and the extent to which the option is selfdetermined (Berkman, Livingston, \& Kahn, 2017; Ryan \& Deci, 2000). Option costs are based on features like the delay and abstractness of the expected reward, effort required to gain the reward, and opportunity costs (Ainslie, 2001; Fujita, Trope, Liberman, \& Levin-Sagi, 2006; Kurzban, Duckworth, Kable, \& Myers, 2013; Thaler \& Shefrin, 1981; Westbrook et al., 2013). Critically, the calculation of benefits and costs are subjective, noisy, and vary by person and context. These calculations also vary by time such that the same response options might be given different weights by the same person depending on time of day, day of the week, or even based on what that person previously did (Inzlicht, Schmeichel, \& Macrae, 2014; Kool, McGuire, Rosen, \& Botvinick, 2010; Kurzban et al., 2013). Contemporary work in neuroeconomics indicates that this noisy integration of value signals is implemented by the ventromedial prefrontal cortex (Hare, Camerer, \& Rangel, 2009), though other work has also implicated the dorsolateral prefrontal cortex (Tusche \& Hutcherson, 2018).

Some choice models (e.g., Berkman, Hutcherson, et al., 2017) seek to redefine control as nothing more than value-based choice. That is, they seek to eliminate control as a unique process separate from more habitual forms of responding. This view has not been without controversy, however (Shenhav, 2017). In contrast, other choice models strike a middle ground, firmly dual process in their preservation of automatic and controlled processes, yet adding a dimension of choice to the typical dual process mix (Shenhav et al., 2013). According to this view, self-control is a special case of decision-making about whether or not to exert cognitive control. Habitual and controlled forms of processing still compete for dominance in this view, but whether or not someone allocates control is based on the expected value of control as calculated by integrating its expected payoff, the amount of control needed, and the inherent cost in terms of cognitive effort (Shenhav et al., 2013). The dorsal anterior cingulate plays a special role in specifying the currently optimal allocation of control by determining the overall expected value of control (Shenhav, Cohen, \& Botvinick, 2016). If control is deemed worthwhile by the dorsal anterior cingulate cortex, it justifies costly effort (cf. Inzlicht, Shenhav, \& Olivola, 2018).

\section{Resource Model of Self-Control}

Perhaps the most well-known model of self-regulation in social psychology, the resource model or strength model, was first celebrated (Baumeister, Tice, \& Vohs, 2018) then heavily criticized (Friese, Loschelder, Gieseler, Frankenbach, \& Inzlicht, 2019; Inzlicht \& Friese, 2019). The resource model makes two broad points about self-control, defined as the capacity to override undesired behavioral tendencies (Tangney, Baumeister, \& Boone, 2004). First, self-control is based on some central resource that powers all sorts of controlled behaviour, be that picking broccoli over chocolate, treating a racial outgroup in an egalitarian fashion despite prejudicial impulses, or naming the color of words despite habitual word-reading responses. Second, this central self-control resource is limited and runs out with use, like a sort of mental fuel that powers the will.

The most celebrated finding of the resource model is the so-called ego depletion effect, whereby engaging control at Time 1 is thought to deplete the central resource and reduce control at Time 2 . For example, in the very first demonstration of ego depletion, people who forced themselves to eat radishes instead of chocolates subsequently quit faster on unsolvable puzzles than people who did not have to exert self-control (Baumeister, Bratslavsky, Muraven, \& Tice, 1998).

The resource model is primarily a model about time: self-control wanes over time such that people exert less control at Time 2 if they have been continuously 
exerting control at Time 1. Though most studies suggest depletion can occur in as little as a few minutes, more rigorous studies suggest that one (Randles, Harlow, \& Inzlicht, 2017) or four hours (Blain, Hollard, \& Pessiglione, 2016) might be necessary. Likewise, while initial theorizing suggested that what is especially depleting of subsequent control are tasks requiring the inhibition of a learned habit (Baumeister, 2014), more recent work suggests that any effortful task will do (Kool \& Botvinick, 2014; Lin, Saunders, Friese, Evans, \& Inzlicht, in press). This effectively reduced depletion to a form of mental fatigue and possibly boredom (Hockey, 2013; Kurzban et al., 2013; Milyavskaya, Inzlicht, Johnson, \& Larson, 2019).

Despite the resource model inspiring an entire generation of scholars, it has been dogged by numerous controversies, leaving more questions than answers (Inzlicht \& Berkman, 2015). The main controversy is whether the basic ego depletion effect is even replicable, a question that might seem preposterous given the mountain of apparent support (Baumeister, 2019; Hagger, Wood, Stiff, \& Chatzisarantis, 2010). Nonetheless, modern meta-analyses and large pre-registered replications suggest that the ego depletion is either very small or non-existent (Carter, Kofler, Forster, \& McCullough, 2015; Hagger et al., 2016). A second controversy concerns how to explain the ego depletion effect, assuming it is real. While the resource model indicates that some real metabolic resource is diminished by control, alternative accounts pin the effect to changes in motivation and willingness (Inzlicht \& Schmeichel, 2012; Kool \& Botvinick, 2014; Kurzban et al., 2013).

We note that despite the enthusiasm with which the resource model was met, the model contributes rather narrowly to our understanding of self-regulation. It suggests merely that control wanes with continued use, something anticipated by classic work on mental fatigue (Thorndike, 1900) and the vigilance decrement (Mackworth, 1948).

\section{Process Model of Self-Control}

As the field shifts away from the notion of effortful inhibition, recent theorizing suggests that self-control can also be more effortless as a function of using different strategies that prevent the experience of temptation (or conflict) in the first place (Duckworth, Gendler, et al., 2016; Gillebaart \& De Ridder, 2015; Hofmann \& Kotabe, 2012). While there is a lot of emerging work examining which strategies people may use in the pursuit of their goals (e.g., Duckworth,
Milkman, \& Laibson, 2018; Hennecke et al., 2019; Hofmann \& Kotabe, 2012), the most prominent framework that lays the foundation for more strategic self-control is the process model of self-control (Duckworth, Gendler, et al., 2016).

According to various strategy models, strategies are either preventive (proactive) or interventive (reactive) (Braver, 2012; Hofmann \& Kotabe, 2012). Preventive strategies (called situational strategies by the process model) are anticipatory techniques used to minimize the extent to which a desire may emerge at a later point in time. In other words, preventive strategies are tools that people can use to avoid conflict before it ever emerges. According to the process model, such strategies include situation selection (i.e., intentionally choosing to be in an environment that is aligned with one's goal and/or avoids temptation) and situation modification (i.e., changing some aspect of the environment to reduce or remove temptations). For example, a person can avoid the bakery section at the grocery store and simply not buy cookies in the first place (situation selection), or, if the cookies are already in their home (e.g., because their spouse loves cookies), they can be placed in the back of the cupboard so they are "out of sight, out of mind" (situation modification).

Because it is not always possible to prevent self-control conflicts entirely, interventive strategies (called intrapsychic/cognitive strategies by the process model) can be used to cope with existing temptations that conflict with important goals. In other words, interventive strategies are tools that people use to manage already existing conflicts. According to the process model, such strategies include attentional deployment (i.e., directing attention away from a temptation), cognitive change (i.e., focusing on the positive aspects of restraining and/or the negative aspects of giving in), and response modulation (i.e., using willpower or inhibition to simply resist). A person, for example, may avoid looking at cookies on the table when having dinner (attentional deployment), they may think about how calorific the cookies are and how guilty they would feel for cheating on their diet (cognitive change), or they just say "no" and try their best to not eat the cookies (response modulation).

A core feature of strategy models is their ability to describe an array of tools that people can use in order to regulate or minimize their experience of temptation and therefore facilitate goal attainment. Another feature that is unique to the process model, and perhaps one of the reasons why it has become so prominent, is the idea that impulse generation develops in an iterative cycle and so the earlier you intervene, the more effective the 
corresponding strategies should be. This is, the impulse or desire for the temptation becomes stronger as you move throughout the cycle, and so intervening earlier means the desire is weaker and therefore increases your chances of success (e.g., it is easy to not desire cookies that are not in your house compared to when they are staring you down from the countertop). Although there is some evidence supporting this model (Duckworth, White, Matteucci, Shearer, \& Gross, 2016), there has yet to be many empirical investigations comparing the effectiveness of different strategies.

\section{Trait Models of Impulsivity}

A In contrast to the previous models that focus on within person processes, trait models focus on differences between people. Whiteside and Lynam (2001) set out to organize the family of trait measures most typically used in personality and clinical psychology to assess impulsivity and then map out how those reorganized dimensions fit in the space of the Big Five. Like other areas of psychology that had attempted to tackle defining and operationalizing constructs like impulsivity, personality and clinical psychology failed to reach a quick and early consensus, leading to a proliferation of trait measures with mostly murkily overlapping content and little or no clarity on definitional coverage. Relying on theories and measures from the work of clinicians like Cloninger (Cloninger, Przybeck, \& Svrakic, 1991) to Gray's neuropsychological system (Gray \& McNaughton, 2000), Whiteside and Lynam (2001) factor analyzed multiple measures and arrived at a four-factor solution to the riddle that is impulsivity. These four facets have remained constants in their definition of impulsivity and consist of Premeditation (planfulness), Sensation Seeking (the appetite for excitement and risk taking), Urgency (the propensity to act rashly often in response to strong emotions), and Perseverance (similar to the industriousness facet of conscientiousness). While this Urgency-Premeditation-Perseverance-Sensation

Seeking (UPPS) system has been updated and improved upon, it largely remains similar in content to this day.

Unlike other systems that have tried to fit impulsivity into a single dimension, Whiteside and Lynam's (2001) system has always tolerated a multidimensional take on the content of impulsivity that is best understood in the relations of these four domains to the Big Five. In particular, the Premeditation and Perseverance facets lie in the domain of conscientiousness. The Sensation Seeking facet corresponds most strongly to extraversion, whereas the Urgency facet appears to lie somewhere between neuroticism and conscientiousness, which reflects the merger of those two themes in the items of this facet. Specifically, they do not simply assess whether people act rashly, but whether they act rashly in response to feeling bad. In later versions of this system, they recast this as a "Negative Urgency" scale and added a "Positive Urgency" facet but readily admit that these two scales correlate at the limits of reliability (Lynam, personal communication, 2019).

Carver (2005) conducted a similar, if not more exhaustive review of the "impulse and constraint" literature in an attempt to arrive at a personality model of impulse control. Touching on models ranging from Freud (e.g., id, ego, superego), classic trait models like the Five Factor Model of personality, developmental models like Rothbart's temperament model (Derryberry \& Rothbart, 1997; Rothbart, Ellis, Rueda, \& Posner, 2003), Epstein's rational-experiential model (Epstein, 1973; Epstein, Lipson, Holstein, \& Huh, 1992), and biological models (e.g., Gray \& McNaughton, 2000), Carver arrived at a similar, but not perfectly overlapping model of impulse and constraint. He identified a tripartite model consisting of a "control mechanism" that corresponds to constructs like effortful control and conscientiousness that are invoked to countermand impulses for short-term positive rewards in deference to larger, but delayed rewards. The other two components of the model are an "undercontrol" or appetitive system somewhat akin to extraversion or behavioral activation that acts to spur people toward short term positive rewards and an "overcontrol" or braking system. The latter corresponds to behavioral inhibition or fear-based mechanisms that would override approach behaviors. In Carver's system then, impulsive behaviors can be stopped two ways: either because fear of negative repercussions outweighs the rewarding nature of the short-term gains or because of a calculating executive system that weighs costs and benefits in order to prioritize long-term gains.

The two major personality models of self-regulation and self-control therefore share much in common. Both systems incorporate a regulatory function that roughly corresponds to the Big Five domain of conscientiousness, with the UPPS system breaking that down into the two facets of Premeditation and Perseverance, and the Carver system identifying it in its developmental precursor of effortful control. Both systems also incorporate a proxy for the "impulse" or craving excitement seeking component of 
impulse control in the form of sensation seeking in the UPPS and behavioral activation in the Carver system. Where the two systems differ is in how they conceptualize the function of negative affect. In the UPPS system, rather than being a braking system, negative affect contributes to more impulsive activities, whereas in the Carver system, negative affectivity in the form of fear inhibits actions such that people do not act rashly because of the potential negative consequences. Carver does discuss the possibility of negative affectivity contributing to impulsive action, but in the end emphasizes the potential braking role that fear performs in the impulse and constraint system.

These trait models of self-regulation are notable for both concluding that self-regulation or self-control are not unidimensional constructs. There will be little solace for those looking for a simple model of self-regulation encapsulated in one dimension of the Big Five (e.g., conscientiousness). They are also consistent with many of the dual system approaches in social psychology in that they include an emotion-based system that drives people toward or away from action and a cool, calculating component that serves to manage these emotion-based impulses.

\section{Integrating Different Perspectives on Self-Regulation}

Having selectively reviewed multiple models of self-regulation, we next discuss them concerning four points of integration: (1) Levels of analysis, (2) role of conflict, (3) role of emotion, and (4) role of cognitive functioning. In broadly discussing each model along these dimensions, we describe not only how the models converge and diverge, but also illuminate potential blind spots (see Table 1 for an overarching summary).

\section{Levels of Analysis}

Some of the most confusing discrepancies across models of self-regulation exist because they focus on incommensurate levels of analysis. At the broadest level, trait models describe how individuals differ on dimensions related to control and regulation (e.g., impulsivity, conscientiousness), while all of the other models describe intrapsychic processes occurring within people (e.g., making goal-related decisions in the moment). But even these intrapsychic models sometimes focus on different aspects of self-regulation.

A number of models focus on goals, cognitive representations of desired end states. The basic unit of analysis for the cybernetic model (Carver \& Scheier,
1998; Wilkowski \& Ferguson, 2016), perhaps the broadest intrapsychic model, is the goal or set point. While this model also places great importance on conflict monitoring and cognitive operations, both are done with reference to goals. Similarly, goals system theory (Kruglanski et al., 2002), as the name implies, is all about goals: how goals are cognitively represented, the means to achieve them, how goals are prioritized, and how goals are shielded from competitors. Work on implementation intentions nicely complements this work by illustrating an effective intervention to help people commit to goal-congruent actions (Gollwitzer \& Sheeran, 2006).

Numerous models focus on conflict, typically between abstract long-term goals and immediately gratifying temptations. Dual process models focus on conflicts between automatic and impulsive systems, between Systems I and II, in a winner-take-all battle (Hofmann et al., 2009). These models are primarily used to explain outcomes in so-called self-control dilemmas involving some degree of conflict that exists in a particular moment. The process model of self-control (Duckworth, Gendler, et al., 2016) similarly centers on actual or anticipated conflict between mutually exclusive behaviors, one that is expected to bring immediate gratification versus a second that furthers more important goals.

Choice models (Berkman, Hutcherson, et al., 2017; Hare et al., 2009; Sullivan, Hutcherson, Harris, \& Rangel, 2014) focus on how people decide between the various response options available to them at that time. Choices are made by a calculation of costs and benefits for different response options, including how they do or do not relate to valued goals. Finally, the resource model (Baumeister et al., 2007) and its competitors (e.g., Inzlicht et al., 2014; Kool \& Botvinick, 2014) focus on time, examining how control and effort willingness change (typically dwindle) with time on task.

One point of difficulty is the sometimes-inconsistent patterns that emerge when comparing between people (i.e., traits) and within people (i.e., states). For example, one of the more interesting recent findings is that people high in trait self-control and conscientiousness actually engage in less self-control in the moment, mostly because they don't need to (Hill, Nickel, \& Roberts, 2014; Hofmann, Baumeister, Förster, \& Vohs, 2012). Similarly, given its association with better outcomes in school, work, relationships, and health (Moffitt et al., 2011; Roberts et al., 2014), self-control is unambiguously positive at the trait level, whereas the act of wrestling with temptations in the 
Table 1. Summary of self-regulation models across key points of integration.

\begin{tabular}{|c|c|c|c|c|}
\hline $\begin{array}{c}\text { Theory/Model } \\
\text { (Key Citation) }\end{array}$ & Level of Analysis & Conflict & Emotions & Cognitive Functioning \\
\hline $\begin{array}{l}\text { Cybernetic Model } \\
\text { (Carver \& Scheier, 1998) }\end{array}$ & $\begin{array}{l}\text { Goal: the focus is on the target goal } \\
\text { or set point, with feedback loops } \\
\text { comparing current and desired states }\end{array}$ & $\begin{array}{l}\text { Conflict is represented as a } \\
\text { discrepancy between current and } \\
\text { desired end states }\end{array}$ & $\begin{array}{l}\text { Positive emotions arise when the } \\
\text { discrepancy between current and } \\
\text { desired states is sufficiently reduced; } \\
\text { negative emotions occur when } \\
\text { discrepancy reduction is not met }\end{array}$ & $\begin{array}{l}\text { Although involved in many aspects } \\
\text { of this model, cognitive functioning } \\
\text { is most prevalent during goal setting } \\
\text { and when monitoring goal progress }\end{array}$ \\
\hline $\begin{array}{l}\text { Goal Systems Theory } \\
\text { (Kruglanski et al., 2002) }\end{array}$ & $\begin{array}{l}\text { Goal: the focus is on the structure of } \\
\text { goals and the means to achieve them }\end{array}$ & $\begin{array}{l}\text { No explicit mention of conflict, but } \\
\text { the idea of goal conflict is inherently } \\
\text { assumed (e.g., having to choose } \\
\text { between conflicting goals or means) }\end{array}$ & $\begin{array}{l}\text { Positive emotions arise as a function } \\
\text { of goal attainment; negative } \\
\text { emotions emerge from experiences } \\
\text { of failure }\end{array}$ & $\begin{array}{l}\text { Cognitive functioning is necessary } \\
\text { when trying to decide between } \\
\text { which goals and their affiliated } \\
\text { means to pursue }\end{array}$ \\
\hline $\begin{array}{l}\text { Resource Model of } \\
\text { Self-Control } \\
\text { Baumeister et al., 2018) }\end{array}$ & $\begin{array}{l}\text { Time: the focus is on how } \\
\text { self-control or willingness to exert } \\
\text { effort wanes over time }\end{array}$ & $\begin{array}{l}\text { Traditional view suggests that the } \\
\text { ability to inhibit conflicting desires } \\
\text { wanes over time; alternate views } \\
\text { suggest that effort is more central } \\
\text { (although both conflicted and } \\
\text { unconflicted effort are possible) }\end{array}$ & $\begin{array}{l}\text { Continuous exertion of self-control } \\
\text { leads to negative emotions (e.g., } \\
\text { frustration, boredom) }\end{array}$ & $\begin{array}{l}\text { The role of cognitive functioning is } \\
\text { unclear; it is not clear whether it is } \\
\text { cognitive function or volitional (i.e., } \\
\text { non-cognitive) processes that decline } \\
\text { with exertion }\end{array}$ \\
\hline $\begin{array}{l}\text { Dual Process Models } \\
\text { (Hofmann et al., 2009) }\end{array}$ & $\begin{array}{l}\text { Conflict: the focus is on the conflict } \\
\text { between "hot" (System I) and "cold" } \\
\text { (System II) processes }\end{array}$ & $\begin{array}{l}\text { System I is dominant in the absence } \\
\text { of conflict to preserve System II } \\
\text { resources. When conflict arises, } \\
\text { System II becomes activated in order } \\
\text { to combat temptations }\end{array}$ & $\begin{array}{l}\text { Inherently assumes that conflict is } \\
\text { aversive (and therefore generates } \\
\text { negative emotions), whereas } \\
\text { temptations generate appetitive } \\
\text { emotions (e.g., desire) }\end{array}$ & $\begin{array}{l}\text { Cognitive function is housed within } \\
\text { System II (i.e., the more deliberate } \\
\text { and controlled system) }\end{array}$ \\
\hline $\begin{array}{l}\text { Process Model of } \\
\text { Self-Control } \\
\text { (Duckworth et al., 2016) }\end{array}$ & $\begin{array}{l}\text { Conflict (anticipated or actual): } \\
\text { the focus is on strategies that help to } \\
\text { avoid or reduce conflict }\end{array}$ & $\begin{array}{l}\text { Conflict between a temptation and a } \\
\text { long-term goal (either anticipated or } \\
\text { actual) is a necessary requirement } \\
\text { for self-control (e.g., goal-goal } \\
\text { conflicts are separate and do not } \\
\text { require self-control) }\end{array}$ & $\begin{array}{l}\text { Inherently assumes that conflict is } \\
\text { aversive (and therefore generates } \\
\text { negative emotions), whereas } \\
\text { temptations generate appetitive } \\
\text { emotions (e.g., desire) }\end{array}$ & $\begin{array}{l}\text { Cognitive functioning is necessary } \\
\text { when trying to decide which } \\
\text { strategies to use in response to a } \\
\text { (potential) temptation }\end{array}$ \\
\hline $\begin{array}{l}\text { Choice Models } \\
\text { (Berkman et al., 2017) }\end{array}$ & $\begin{array}{l}\text { Choice: the focus is on how people } \\
\text { weigh the different options that are } \\
\text { saliently available to them, with the } \\
\text { most valued option being selected }\end{array}$ & $\begin{array}{l}\text { Conflict is not required, but can } \\
\text { manifest if different choice options } \\
\text { are similar in value, thus making it } \\
\text { hard to choose one over the other }\end{array}$ & $\begin{array}{l}\text { Having choice options that are } \\
\text { similarly valued generates negative } \\
\text { emotions (e.g., anxiety), even when } \\
\text { both options lead to positive } \\
\text { outcomes }\end{array}$ & $\begin{array}{l}\text { Cognitive functioning is necessary } \\
\text { when trying to decide between } \\
\text { different choice options }\end{array}$ \\
\hline $\begin{array}{l}\text { Trait Models of } \\
\text { Impulse Control } \\
\text { (Roberts et al., 2014; } \\
\text { Whiteside \& Lynam, 2001) }\end{array}$ & $\begin{array}{l}\text { Trait: the focus is on individual } \\
\text { differences in general self-regulatory } \\
\text { dimensions (e.g., conscientiousness) }\end{array}$ & $\begin{array}{l}\text { While not prominently featured, } \\
\text { conflict may stem simply from the } \\
\text { need to regulate a desire; traits may } \\
\text { also aid in conflict avoidance }\end{array}$ & $\begin{array}{l}\text { Both positive and negative emotions } \\
\text { play a role in self-regulation, } \\
\text { although both can either facilitate or } \\
\text { hinder self-regulation }\end{array}$ & $\begin{array}{l}\text { Individual differences in cognitive } \\
\text { ability and self-regulation both } \\
\text { independently predict many of the } \\
\text { same outcomes }\end{array}$ \\
\hline
\end{tabular}


moment is often associated with negative outcomes, including more negative affect (Inzlicht, Bartholow, \& Hirsh, 2015; Kurzban, 2016; Saunders, Milyavskaya, \& Inzlicht, 2015). How can one reconcile these conflicting patterns?

One argument would be that the different levels of analysis reflect qualitatively different systems. This might be best demonstrated using an analogy differentiating between weather and climate. While climate reflects broad patterns that slowly change over time (i.e., traits), weather (i.e., states) changes day to day; while on average weather is related to climate, it is relatively unrelated at any given moment. For example, it might be distressing to forego an immediate reward in the moment, like ice cream; but, in the aggregate and over time, people are generally satisfied when they meet their dieting goals.

Alternatively, it is increasingly common to conceptualize the various levels represented by these models as part of the same system. For example, models that treat traits as density distributions of states (Fleeson, 2001) conceive of the lower-order processes as potential components of a broader, complex system of related modules. These models presume less distance between the higher and lower levels of the system than entailed by the climate-weather analogy would indicate. Therefore, it would be problematic to find completely opposing patterns for seemingly similar concepts that have been operationalized at different levels of analysis like has been found in prior research on self-control. At this time, we do not feel there is sufficient information in the empirical data to know which of these perspectives is more correct.

\section{Role of Cognitive Conflict}

We might describe numerous models as conflict models because conflict is a necessary feature of what is to be explained. The process model explains the various strategies people use to control themselves, with control defined as the conflict between proximal and distal motives (Duckworth, Gendler, et al., 2016). The process model, that is, begins with conflict; without actual or anticipated conflict, there is nothing to be explained. Dual process models of control also begin with conflict during so-called self-control dilemmas where there is tension between the habitual and control systems (Heatherton \& Wagner, 2011; Hofmann et al., 2009). Without conflict, the habitual system is dominant, as the control system is used sparingly given its inherent costliness (Cohen, 2017). According to conflict monitoring theory (Botvinick et al., 2001), conflict is what instigates the control system, with later refinements to this model broadening the scope of conflict to include performance errors, prediction errors, and expectancy violations (Kool et al., 2017). The cybernetic model (Carver \& Scheier, 1998) also places conflict detection as a central feature, though what is being detected here is softer than conflict and might be better construed as a discrepancy between desired and current states. The point here is that numerous models center on conflict; without conflict, the models are either silent or suggest that control is not engaged as default habitual responding predominate.

It might be tempting to call the resource model a conflict model since it describes the inhibition of conflicting desires that wanes over time (Baumeister, 2014). Without conflict, in other words, there is nothing to restrain and nothing that wanes over time. However, alternatives to the resource model (Inzlicht, Schmeichel, et al., 2014; Kurzban et al., 2013) focus less on inhibition, and instead suggest that it is the provision of effort, even unconflicted effort (e.g., driving during a snowstorm), that wanes over time (Lin et al., in press).

It is important to note that in the conflict models above, conflict is limited to the battle between proximal and distal motives, between immediate urges and enduring goals, or between System I and System II. But, given that time is limited, with every choice of action coming at the cost of other possible actions (i.e., opportunity costs), conflicts between two enduring goals also arise. However, these models are silent about goal-goal conflicts, such as when deciding whether to finish a manuscript or to make an elaborate family meal. Choice models (Berkman, Hutcherson, et al., 2017; Hare et al., 2009), in contrast, do not dichotomize processes as habitual or automatic, and as such can accommodate a wider variety of conflicts, the resolution of which determines behavioural enactment.

A number of models avoid this conflict trap, accommodating both conflicted and unconflicted goal pursuit. Choice models, for example, do not require conflict at all, as they view control as the product of value-based decisions. Thus, some decisions are easy and relatively unconflicted while others are harder because the value of the various response options are similar in expected utility. Because conflict is not a necessary feature of these models, these models have a broader range of applicability.

Goal systems theory also does not focus on conflict, though it can readily accommodate it when incompatible goals are activated within a goal network 
(Kruglanski et al., 2002). Goal conflict produces an aversive state (Proulx, Inzlicht, \& Harmon-Jones, 2012) that must be resolved by either selecting a multifinal means to advance both goals simultaneously or by devaluing one goal to give precedence to the other. Goals differ in importance, with important goals being prioritized automatically and shielded from interference by competing goals. For example, if the goal to "eat healthy" is salient, not only will this activate corresponding means (e.g., eat salad), it will deactivate means for the alternative goal to "eat tasty food" (Shah et al., 2002).

Although not entirely absent, conflict also plays a less prominent role in trait models. More accurately, trait models assume conflict in the structural dimensions that make up the models of self-regulation. For example, Carver (2005) highlights how the interplay between approach, avoidance, and regulatory mechanisms is predicated on the existence of a stimulus that would lead one to want to do something and potentially need to regulate that desire. Similarly, the UPPS model (Whiteside \& Lynam, 2001) assumes that urgency clashes with factors like premeditation to guide behavior when faced with highly tempting stimuli like drugs and alcohol. What is lacking in each of these models is an explicit conceptualization of conflict: how is conflict processed by an individual? How do components of the model combine or interact to resolve that conflict?

Another aspect of trait models is the idea that certain people can effectively avoid conflict and through doing so appear to be more self-regulated. In particular, conscientiousness, the core component of self-control, is thought to lead to patterns and outcomes that appear quite relevant to conflict dilemmas but do so by simply avoiding them. For example, the Invest and Accrue model of conscientiousness (Hill \& Jackson, 2016) suggests that by putting effort into socially valued actions like achievement activities in school and work, conscientious people reap rewards, such as better socioeconomic status and higher relationship satisfaction. Similarly, it is thought that conscientiousness leads to better relationship outcomes, not only because of valuing positive relationship behaviors but because conscientious people avoid actions, like infidelity that typically cause relationship distress (Hill et al., 2013). Conscientious people can therefore reap positive rewards through their ability to sidestep conflict. In this sense, effective self-regulation might be better understood as avoiding conflict rather than overcoming it (Hofmann, Baumeister, et al., 2012).

\section{Role of Emotion}

The role of emotion in self-regulation has been under-developed, typically implied though seldom stated explicitly. The major exception to this pattern of insufficient elaboration comes from trait models. Viewed broadly, certain people are dispositionally appetitive and thus have stronger cravings for actions that undermine long-term goals. The two trait models we discussed (Carver, 2005; Whiteside \& Lynam, 2001) differ only in how they conceptualize negative affect in this role, with the possibility that negative affect plays both approach and avoidance roles.

There are other emotional aspects of the components of self-regulation, especially conscientiousness, that complicate the role of emotions, however. In particular, high conscientiousness is positively associated with both positive affect (Fayard, Roberts, Robins, \& Watson, 2012) and life satisfaction (DeNeve \& Cooper, 1998). This complicates our understanding of the Carver and UPPS models of self-regulation, as positive emotions are typically thought to be the reason why people choose short-term actions over long-term outcomes. Of course, these associations may be the result of individuals navigating life more effectively and subsequently feeling good about their successes (Hill \& Jackson, 2016). At a minimum, it seems positive emotions facilitate both impulsive short-term actions and long-term achievements that necessitate successfully delaying gratification.

What is more interesting is that conscientiousness and related traits (e.g., self-control) are strongly associated with both positive and negative self-conscious emotions. Self-conscious emotions reflect one's concern about the self in relation to letting down or impressing others (Tracy \& Robins, 2004). Highly conscientious individuals, for example, tend to be more prone to feel guilt while simultaneously experiencing less guilt (Fayard et al., 2012). Conversely, these individuals feel more authentic pride than others. So, clearly, the control aspect of self-control appears to be unambiguously related to positive and negative affect, but aspects of emotion have not been previously considered in self-control models.

While prior trait models did not formally incorporate the emotional topography related to self-regulation, these findings may clarify how a self-regulating system works. For example, there is little evidence that a fear-based braking mechanism (Carver, 2005) coheres with the other elements of self-regulation, such as urgency and conscientiousness. 
However, if the braking system is instead reconstrued as guilt, it provides insight into how a braking mechanism would work. People avoid doing rash things, in part, because of the perceived social consequences that could diminish their reputation, whether real or imagined. The broader positive affective correlates of traits like conscientiousness also provide a much-needed mechanistic insight into why people would delay gratification. If the habit of delaying gratification results in increased pride and life satisfaction, this would explain why people learn to avoid temptation as they come to understand that the long-term affective consequences of self-control exceed the short-term positive affect that comes from indulging in momentary desires.

Emotion is thus at the core of trait models, clarifying that positive emotion is involved in both tempting people away from their goals but also in rewarding people for persistence; they also clarify the facilitating role of negative emotion, specifically the anticipation or experience of guilt (Fayard et al., 2012). Contrasting these nuanced contributions, insights about the role of emotion in intrapsychic models are modest. The process model and dual process models both describe temptations as typically appetitive emotions that detract from goal pursuit (Duckworth, Gendler, et al., 2016; Hofmann et al., 2009). These conflict models further suggest that conflict is aversive, bringing up feelings of anxiety, frustration, and effort (Dreisbach \& Fischer, 2015; Saunders, Lin, Milyavskaya, \& Inzlicht, 2016; Spunt, Lieberman, Cohen, \& Eisenberger, 2012), which potentially explain why such conflicts tend to be avoided (Kool et al., 2010). Similarly, choice models describe options that are similarly valued as generating feelings of anxiety, even when both choice options lead to positive outcomes (Lin, Saunders, Hutcherson, \& Inzlicht, 2017; Shenhav \& Buckner, 2014). Finally, alternatives to the resource model suggest that the continuous exertion of self-control produces feelings of fatigue, frustration, and boredom (Lin et al., in press; Milyavskaya, Inzlicht, et al., 2019), which act as stop signals that incite the search for more gratifying pursuits (Hockey, 2013). In sum, these intrapsychic models mostly suggest that emotion interferes with self-regulation: emotions are at the root of temptations, arise with conflict, and demotivate effort expenditure over time.

Other intrapsychic models view emotions more completely. Goal systems theory indicates that positive affect arises through goal attainment, whereas negative affect arises with failure (Kruglanski et al., 2002). The specific emotions experienced range from relief to guilt, from pride to disappointment, depending on whether the goals relate to avoidance and approach, respectively (Higgins, Shah, \& Friedman, 1997). More complete still, the cybernetic model suggests that the feedback process is accompanied by attendant feeling states that are produced by a second-order feedback system (Carver \& Scheier, 2011). This second-order system imputes the rate of reduction in the discrepancy between desired and actual states and compares this rate to a desired rate of discrepancy reduction. When the actual discrepancy reduction rate meets or exceeds expectations, positive affect arises; when the discrepancy reduction rate is slower than expected, negative affect arises. These emotions signal to a person that they are doing better or worse than expected, which might impel them to engage less or more effort, respectively.

\section{Role of Cognitive Functioning}

Cognitive functioning refers to the processes of reasoning, planning, thinking, solving problems, understanding, and learning (Gottfredson, 1997). Just like self-regulation can be construed as traits or states, cognitive functioning can refer to individual differences in intelligence or cognitive ability, or refer to the cognitive processes recruited in the moment to solve specific self-control dilemmas.

At the trait level, there is a long history of examining and comparing trait measures of self-regulation (e.g., conscientiousness) and intelligence on various beneficial life outcomes, such as academic achievement, health, and occupational status (e.g., Chamorro-Premuzic \& Furnham, 2008; Duckworth et al., 2019; Duckworth, Weir, Tsukayama, \& Kwok, 2012). From these analyses, two themes emerge. First, both cognitive ability and self-regulation (so-called non-cognitive factors) independently predict life outcomes. That is, both the ability to doggedly pursue goals and the ability to reason and learn are important longitudinal predictors of success (e.g., Duckworth et al., 2019). Second, empirical study after empirical study has shown near zero or even negative associations between traditional measures of cognitive ability or intelligence and self-regulation (ChamorroPremuzic \& Furnham, 2008; Moutafi, Furnham, \& Paltiel, 2004; Zajenkowski \& Stolarski, 2015).

Intrapsychic models of self-regulation focus less on individual differences in cognitive ability and instead focus on the various cognitive processes that contribute to self-regulation in the moment. The clearest articulation of cognitive functioning comes from dual 
process models, where cognitive functioning resides as the deliberate and controlled System II, doing battle with the more habitual, emotional, and automatic System I. Habitual responses are the default, in this view, with cognitive processes only coming online when some form of conflict is detected (Botvinick et al., 2001).

The process model makes a similar point: Indulging temptations are the default and are thus mindless habits; cognitive processes only come into play when conflict is experienced or anticipated and therefore require the use of self-control strategies (Duckworth, Gendler, et al., 2016). The process of choosing between competing options is also where cognitive functioning resides in choice models. This process consists of calculating and integrating the various costs and benefits of each option and then selecting the one with the greatest value (Berkman, Hutcherson, et al., 2017). Choice is again at the center in goal systems theory, where cognitive processes take the form of choosing between the various means to pursue a given goal (Kruglanski et al., 2002). However, there is considerable variation in the ability to choose between various means to pursue goals, either as a function of within-person fluctuations (e.g., fatigue, inebriation) or between-person differences (e.g., intelligence), meaning that some people, some of the time are better able to pursue multiple goals via multifinal means while experiencing relatively little conflict. The act of choosing between various options, then, is the principle cognitive process for the process model, choice models, and goal systems theory.

Cognitive functioning is arguably located in every element of the cybernetic feedback loop, but especially during goal setting and monitoring goal progress (Carver \& Scheier, 1998). Attempting to reduce the discrepancy between the current and desired state might involve cognitive functioning-for example by making choices, paying deeper attention, or suppressing conflicting desires-but it could also involve less cognitive, more motivational processes as well. Finally, cognitive functioning plays an unclear role in the resource model. Inhibitory control is thought to decline over time, but it is unclear whether this decline occurs in the various cognitive processes that facilitate control (Baumeister et al., 2007) or the volitional processes that shape the degree to which control is engaged (Inzlicht \& Schmeichel, 2012).

\section{Prescriptions for Future Research}

By discussing each of the models with respect to level of analysis, conflict, emotion, and cognitive functioning, we have identified several commonalities and points of convergence. More important, perhaps, our discussion pinpoints areas where there has been insufficient emphasis, an elaboration of which can offer prescriptions for future research.

\section{Level of Analysis}

Each of the models address self-regulation from different levels of analysis, from a focus on differences between people at the broadest level to a focus on goals at the narrowest level, with attention to time, conflict, and choice somewhere in the middle (see Table 1). That each model covers a different focal point is a strength of the literature, assuring that self-regulation is described in all its facets. Problems arise, though, when models talk past one another because of inadequate integration across these levels of analysis or when findings from one level of analysis are assumed to generalize to a separate level. Such problems have already arisen, most notably when discrepancies were discovered between trait models and state models.

For example, after noting robust associations between various trait measures of self-regulation and important life outcomes (Duckworth \& Seligman, 2005; Moffitt et al., 2011; Tangney et al., 2004), scholars attributed poor outcomes to people's failure to engage (state) self-regulatory processes in the moment (Duckworth \& Seligman, 2005) and variously recommended that people use more (state) self-control in their daily lives (Baumeister \& Tierney, 2011; Inzlicht, Legault, \& Teper, 2014). These conclusions are contingent on strong coherence between trait and state self-regulation; they assume that people high in trait measures of self-control also use more self-control in the moment. Recent research, however, suggests that people high in trait measures of self-regulation actually engage in less state self-control (Hill et al., 2014; Hofmann, Baumeister, et al., 2012); there is also preliminary evidence that, in contrast to trait self-control, state self-control (specifically inhibition) is unrelated to goal attainment (Milyavskaya \& Inzlicht, 2017). Thus, people high in trait measures of self-regulation are likely more successful because they find alternative ways to self-regulate. The point here is that ignoring differences between levels of analysis has consequences. 
We need to respect these different levels of analysis, but also work harder to bridge across them. It would be ideal if researchers would systematically incorporate different levels of analysis in their research. By this we don't mean that dispositional self-control researchers should use experiments in their broad surveys or that experimentalists should measure traits. Instead, we propose that a true integration and testing of these perspectives would come only from assessing molecular, putatively process-oriented models over very long periods of time so as to empirically identify the different levels in the system (see Roberts, 2018). That is, we recommend that scholars start assessing the various processes thought to underlie self-regulation (e.g., value-based choices, declines in effort willingness over 30-minutes) repeatedly over many months and even years, and then determining how these processes change over time within people, but also how they cohere between people.

\section{Conflict}

Conflict plays an important role in nearly all the models we reviewed. Some models place conflict at the hub, describing how conflict (real or anticipated) is resolved (Duckworth, Gendler, et al., 2016; Heatherton \& Wagner, 2011; Hofmann et al., 2009), how successful conflict resolution wanes over time (Baumeister et al., 2007), or how conflict is monitored (Carver \& Scheier, 1998). In contrast, goal systems theory, choice models, and trait models place comparatively less emphasis on conflict. These models can accommodate conflict, but they do not privilege it. Given the centrality of conflict to so many models, some scholars, including ourselves, have made bold claims to the effect that resolving conflict is at the heart of self-regulatory success (e.g., Inzlicht et al., 2015).

We now wonder, though, if conflict has been overemphasized, if the near exclusive focus on conflict by many models has been to the field's detriment. We ask because new work suggests that the biggest drag on goal attainment is not the inability to resolve conflict (i.e., lack of self-control), but the presence of conflicting desires and temptations to begin with (Milyavskaya \& Inzlicht, 2017; see also, Wilkowski, Ferguson, Williamson, \& Lappi, 2018). Once conflict is present, in other words, successful self-control in the moment does not necessarily translate to successful self-regulation in the end. Further, as mentioned above, the people who are most skilled at self-regulation are actually spending less time overcoming conflict, not more (Hill et al., 2014). One reason they might spend less time overcoming conflict is that they adaptively jettison goals that are unattainable or that conflict too much with current states (Wrosch et al., 2003). Effective self-regulation, that is, involves not only doggedly pursuing goals, but also knowing when to abandon goals (e.g., those requiring too much effortful control). Our near exclusive focus on conflict and overcoming conflict might have been a distraction.

Models that describe goal pursuit more generally (e.g., Berkman, Hutcherson, et al., 2017), without such a focus on conflict, are therefore of great benefit. The process model, for example, offers strategies (e.g., situation selection) that describe how conflict can be avoided before it arises (Duckworth, Gendler, et al., 2016). Older work on the concept of pre-commitment similarly promises effective self-regulation without the need to overcome conflict in the moment (Ariely \& Wertenbroch, 2002; Crockett et al., 2013) . Even more useful, we think, is work focused on the motivational structure of people's goals (Ryan \& Deci, 2000). When people truly identify with their goals, when they truly want-to accomplish them for autonomous reasons, they are not tempted or conflicted by other desires (Milyavskaya, Inzlicht, Hope, \& Koestner, 2015; Werner \& Milyavskaya, 2018). This suggests they can accomplish such goals without the need for control (Berkman, Livingston, et al., 2017; Ryan \& Deci, 2000). People who are skilled self-regulators seem to know this, as they naturally identify autonomous reasons for their actions (Converse, Juarez, \& Hennecke, 2019), thereby structuring their goals to be conflict-resistant. Finally, we advise greater attention not only to how people set goals (Locke \& Latham, 2006), but also how people make plans to accomplish them (Ludwig et al., 2019; Ludwig, Srivastava, \& Berkman, 2018). While such plans can involve anticipating and planning for conflicts (Duckworth, Grant, Loew, Oettingen, \& Gollwitzer, 2011; Oettingen et al., 2009), planfulness also involves conflict-free cognitive orientations, such as valuing the future self and considering future implications of one's present behavior. We thus prescribe less focus on self-control and a greater focus on conflict-free means of self-regulation.

\section{Emotion}

In stark contrast to the overemphasis on conflict, we believe the role of emotion has been underdeveloped, if not caricatured. For millennia, emotion been seen as the enemy of rational pursuits, including self-control. We can see this legacy of classical thought most clearly in 
dual process models, some versions of which suggest behavior is determined by some battle between hot emotion and cold cognition (Kahneman, 2011). But, even when emotion is viewed with a modern constructionist lens, emotion is still equated with temptation, as the thing that distracts people away from their goals (Duckworth, Gendler, et al., 2016; Gross, 2015). One notable exception is work on traits, which view emotions more neutrally, more completely: Emotions are parts of the mind and body that both detract (e.g., impulsive desire) and enhance (e.g., guilt, anxiety) self-regulation.

Given the overemphasis on emotion as the enemy of control, we advise more research on how emotion is integrated with and perhaps sometimes facilitative of control. Recent work on the affective signaling hypothesis, for example, suggests that emotions can indicate both when cognitive control is needed and when conflict is resolved (Dignath, Eder, Steinhauser, $\&$ Kiesel, 2020). Other exciting work indicates that real world self-control failure is predicted by the extent to which the brain's valuation system (i.e., ventromedial prefrontal cortex) responds to anticipated long-term consequences of present-moment behavior (Kronke et al., in press). In other words, the more people value and presumably respond emotionally to anticipated future outcomes, the more self-control they tend to have. Finally, emotion can be facilitative of self-control to the extent that people avoid behaviors that generate negative feelings. We already mentioned guilt, whereby conscientious people are more guilt prone and thus tend to avoid behaviors that may lead them to feel guilty (Fayard et al., 2012). A similar dynamic may be at play with regret, which not only spoils the pleasure of giving into temptation (Hofmann, Kotabe, \& Luhmann, 2013; but see Becker, Jostmann, Hofmann, \& Holland, 2019), but might also steer people away from giving into temptation as they anticipate regret in the future (Vosgerau, Scopelliti, \& Huh, 2020).

\section{Cognitive Functioning}

Psychometricians sometimes talk about JingleJangle fallacies. The Jingle fallacy manifests when two constructs are thought to be the same because they bear the same name, but are actually different. For example, it was long assumed that self-control and cognitive control referred to the same general construct (e.g., Inzlicht, Schmeichel, et al., 2014), though there is now strong evidence that measures of each are unrelated to one another (Dang et al., 2020; Saunders et al., 2018). The Jangle fallacy, in contrast, manifests when two highly similar things are thought to be wholly distinct because they bear different names. Here, we wonder if some corners of the field committed the Jangle fallacy by thinking that self-regulation was being studied when in fact what was being studied was actually intelligence (e.g., Mischel, Shoda, \& Rodriguez, 1989). After all, both self-regulation and intelligence independently predict important life outcomes (Duckworth et al., 2019), yet they mostly appear unrelated, at least at the trait level (e.g., Zajenkowski \& Stolarski, 2015).

Given that self-regulatory ability and cognitive ability are distinct, yet predict many of the same outcomes, confusion can arise when measuring one without the other. For example, one could mistakenly assume that self-regulation is important for various beneficial outcomes when in reality cognitive ability or intelligence is the key. For example, when measures of cognitive control or executive function predict important real-life outcomes, it is tempting to make inferences about the power of self-regulation (e.g., Hofmann, Schmeichel, et al., 2012). However, despite their definitional similarity, measures of cognitive control are more closely related to general intelligence (Engelhardt et al., 2016; Jewsbury et al., 2016) than to various measures of self-regulation (Eisenberg et al., 2019; Saunders et al., 2018). That is, many of us have gone to great efforts to study cognitive control, believing it would say something meaningful about self-regulation; instead, we now wonder if we were studying the broad abilities that underlie intelligence instead (Jewsbury et al., 2016).

Similarly, despite the wildly popular work linking children's ability to delay the gratification of eating marshmallows with later cognitive and socioemotional development (Mischel et al., 1989), this work might say remarkably little about self-regulation. While a large replication of this seminal work replicated the basic connection between delay time in childhood and some (though not all) of the original outcome measures later in life, when controls for cognitive ability (and socioeconomic factors) were included, delay time was no longer predictive (Watts, Duncan, \& Quan, 2018). That is, unlike other longitudinal work suggesting that childhood self-control predicts important life outcomes over and above the effect of intelligence (Moffitt et al., 2011), the marshmallow studies could not. In other words, these findings suggest that cognitive ability (and other factors) plays a much larger role than previously anticipated (Watts et al., 2018).

Our point here is that we need to avoid the Jangle fallacy, specifically by avoiding the conflation of self-control and intelligence. To accomplish this, not 
only should scholars routinely assess intelligence in studies of self-regulation, as is common among trait researchers (Duckworth \& Seligman, 2005; Moffitt et al., 2011), they should do more to incorporate a role for intelligence in theorizing about self-regulation. Is it possible that the various processes thought to underlie and describe self-regulation (e.g., choosing the best means to achieve a goal; overcoming short-term temptations) are actually different aspects of intelligence? This departs from the way self-regulation has been discussed in the past; and we don't want to overstate things - trait studies have indicated that both cognitive and noncognitive factors are important (Duckworth et al., 2019). Nonetheless, we believe that the overlap between intelligence and self-regulation has been underemphasized, and we prescribe better integration of these concepts in the future.

\section{Conclusion}

In discussing the various models of self-regulation side-by-side, it is tempting to try to combine them into a single comprehensive model. We avoided such temptation here because, in our view, some of the models barely made contact with one another to make combination useful. This was most evident in the gulf between trait models and more process-oriented accounts. Instead, and as a first step, we compared each model on four dimensions to identify points of convergence and points of understatement. Such an analysis yielded a number of novel insights. These include the need to examine the processes underlying self-regulation longitudinally, the need to move beyond conflict, an appreciation for how emotions facilitate self-regulation, and a need to integrate the processes underlying self-regulation with those underlying intelligence.

People high in self-control, low in impulsivity live the good life. They are healthier, happier, wealthier, and more law-abiding than their less controlled, more impulsive peers (Moffitt et al., 2011). The question we asked here is what research has to say about why they live the good life and how they make better choices. By contemplating how various research traditions differentially construe the concept of self-regulation, we hope a truly comprehensive account will one day emerge.

\section{References}

Ainslie, G. (1974). Impulse control in pigeons. Journal of the Experimental Analysis of Behavior, 21(3), 485-489.
Ainslie, G. (2001). Breakdown of will. Cambridge University Press.

Alexander, W. H., \& Brown, J. W. (2011). Medial prefrontal cortex as an action-outcome predictor. Nature Neuroscience, 14(10), 1338-1344.

Apps, M. A. J., Grima, L. L., Manohar, S., \& Husain, M. (2015). The role of cognitive effort in subjective reward devaluation and risky decision-making. Scientific Reports, 5,16880 .

Ariely, D., \& Wertenbroch, K. (2002). Procrastination, deadlines, and performance: Self-control by precommitment. Psychological Science, 13(3), 219-224.

Baumeister, R. F. (2014). Self-regulation, ego depletion, and inhibition. Neuropsychologia, 65, 313-319.

Baumeister, R. F. (2019). Self-Control, Ego Depletion, and Social Psychology's Replication Crisis. In A. Mele (Ed.), Surrounding Self-Control. New York: Oxford.

Baumeister, R. F., Bratslavsky, E., Muraven, M., \& Tice, D. M. (1998). Ego depletion: is the active self a limited resource? Journal of Personality and Social Psychology, 74, 1252-1265.

Baumeister, R. F., Heatherton, T. F., \& Tice, D. M. (1994). Losing control: How and why people fail at self-regulation. San Diego: Academic Press.

Baumeister, R. F., Tice, D. M., \& Vohs, K. D. (2018). The Strength Model of Self-Regulation: Conclusions From the Second Decade of Willpower Research. Perspectives on Psychological Science, 13(2), 141-145.

Baumeister, R. F., \& Tierney, J. (2011). Willpower: Rediscovering the Greatest Human Strength. New York, NY: Penguin Press HC.

Baumeister, R. F., Vohs, K. D., \& Tice, D. M. (2007). The Strength Model of Self-Control. Current Directions in Psychological Science, 16(6), 351-355.

Becker, D., Jostmann, N. B., Hofmann, W., \& Holland, R. W. (2019). Spoiling the Pleasure of Success: Emotional Reactions to the Experience of Self-Control Conflict in the Eating Domain. Emotion, 19, 1377-1385.

Berkman, E. T., Falk, E. B., \& Lieberman, M. D. (2011). In the Trenches of Real-World Self-Control. Psychological Science, 22(4), 498-506.

Berkman, E. T., Hutcherson, C. A., Livingston, J. L., Kahn, L. E., \& Inzlicht, M. (2017). Self-Control as Value-Based Choice. Current Directions in Psychological Science, 26(5), 422-428.

Berkman, E. T., Livingston, J. L., \& Kahn, L. E. (2017). Finding The "Self" in Self-Regulation: The Identity-Value Model. Psychological Inquiry, 28(2-3), 77-98.

Blain, B., Hollard, G., \& Pessiglione, M. (2016). Neural mechanisms underlying the impact of daylong cognitive work on economic decisions. Proceedings of the National Academy of Sciences, 113(25), 6967-6972.

Botvinick, M. M., Braver, T. S., Barch, D. M., Carter, C. S., $\&$ Cohen, J. D. (2001). Conflict monitoring and cognitive control. Psychological Review, 108, 624-652.

Braver, T. S. (2012). The variable nature of cognitive control: a dual mechanisms framework. Trends in 
Cognitive Sciences, 16(2), 106-113.

Buckholtz, J. W. (2015). Social norms, self-control, and the value of antisocial behavior. Current Opinion in Behavioral Sciences, 3, 122-129.

Carter, E. C., Kofler, L. M., Forster, D. E., \& McCullough, M. E. (2015). A Series of Meta-Analytic Tests of the Depletion Effect : Self-Control Does Not Seem to Rely on a Limited Resource. Journal of Experimental Psychology: General, 144(3), 796-815.

Carver, C. S. (2005). Impulse and constraint: Perspectives from personality psychology, convergence with theory in other areas, and potential for integration. Personality and Social Psychology Review, 9(4), 312-333.

Carver, C. S., \& Scheier, M. F. (1998). On the SelfRegulation of Behavior. New York, NY: Cambridge University Press.

Carver, C. S., \& Scheier, M. F. (2011). Self-regulation of action and affect. In K. D. Vohs \& R. F. Baumeister (Eds.), Handbook of self-regulation: Research, theory, and applications (2nd ed., pp. 3-21). New York, NY: Guilford Press.

Chamorro-Premuzic, T., \& Furnham, A. (2008). Personality, intelligence and approaches to learning as predictors of academic performance. Personality and Individual Differences, 44(7), 1596-1603.

Cloninger, C. R., Przybeck, T. R., \& Svrakic, D. M. (1991). The Tridimensional Personality Questionnaire: U.S. normative data. Psychological Reports.

Cohen, J. D. (2017). Cognitive control: Core constructs and current considerations. In T. Egner (Ed.), The Wiley Handbook of Cognitive Control (pp. 3-28). Malden, MA: John Wiley \& Sons.

Converse, B. A., Juarez, L., \& Hennecke, M. (2019). Selfcontrol and the reasons behind Our goals. Journal of Personality and Social Psychology, 116(5), 860-883.

Conway, A. R. A., Kane, M. J., \& Engle, R. W. (2003). Working memory capacity and its relation to general intelligence. Trends in Cognitive Sciences. Elsevier Ltd.

Cowan, N. (2001). The magical number 4 in short-term memory: A reconsideration of mental storage capacity. Behavioral and Brain Sciences, 24(1), 87-114.

Crockett, M. J., Braams, B. R., Clark, L., Tobler, P. N., Robbins, T. W., \& Kalenscher, T. (2013). Restricting temptations: neural mechanisms of precommitment. Neuron, 79(2), 391-401.

Dang, J., King, K.M., \& Inzlicht, M. (2020). Why are selfreport and behavioral measures weakly correlated? Trends in Cognitive Sciences, 24, 267-269.

De Ridder, D. T. D., De Boer, B. J., Lugtig, P., Bakker, A. B., \& van Hooft, E. A. J. (2011). Not doing bad things is not equivalent to doing the right thing: Distinguishing between inhibitory and initiatory self-control. Personality and Individual Differences, 50(7), 1006-1011.

DeNeve, K. M., \& Cooper, H. (1998). The Happy Personality: A Meta-Analysis of 137 Personality Traits and Subjective Well-Being. Psychological Bulletin, 124(2), 197-229.
Derryberry, D., \& Rothbart, M. K. (1997). Reactive and effortful processes in the organization of temperament. Development and Psychopathology, 9(4), 633-652.

Dignath, D., Eder, A. B., Steinhauser, M., \& Kiesel, A. (2020). Conflict monitoring and the affective-signaling hypothesis-An integrative review. Psychonomic Bulletin \& Review.

Doebel, S. (2020). Rethinking executive function development. Perspectives on Psychological Science.

Dreisbach, G., \& Fischer, R. (2015). Conflicts as aversive signals for control adaptation. Current Directions in Psychological Science, 24(4), 255-260.

Duckworth, A. L., Gendler, T. S., \& Gross, J. J. (2016). Situational Strategies for Self-Control. Perspectives on Psychological Science, 11(1), 35-55.

Duckworth, A. L., Grant, H., Loew, B., Oettingen, G., \& Gollwitzer, P. M. (2011). Self-regulation strategies improve self-discipline in adolescents: benefits of mental contrasting and implementation intentions. Educational Psychology, 31(1), 17-26.

Duckworth, A. L., Milkman, K. L., \& Laibson, D. (2018). Beyond Willpower: Strategies for Reducing Failures of Self-Control. Psychological Science in the Public Interest, 19, 102-129.

Duckworth, A. L., Quirk, A., Gallop, R., Hoyle, R. H., Kelly, D. R., \& Matthews, M. D. (2019). Cognitive and noncognitive predictors of success. Proceedings of the National Academy of Sciences of the United States of America, 116(47), 23499-23504.

Duckworth, A. L., \& Seligman, M. E. P. (2005). Selfdiscipline outdoes IQ in predicting academic performance of adolescents. Psychological Science, 16(12), 939-944.

Duckworth, A. L., Weir, D., Tsukayama, E., \& Kwok, D. (2012). Who does well in life? Conscientious adults excel in both objective and subjective success. Frontiers in Psychology, 3(SEP).

Duckworth, A. L., White, R. E., Matteucci, A. J., Shearer, A., \& Gross, J. J. (2016). A stitch in time: Strategic selfcontrol in high school and college students. Journal of Educational Psychology, 108(3), 329-341.

Eisenberg, I. W., Bissett, P. G., Enkavi, A. Z., Li, J., MacKinnon, D. P., Marsch, L. A., ... Poldrack, R. A. (2019). Uncovering the structure of self-regulation through data-driven ontology discovery. Nature Communications, 10(1), 2319.

Engelhardt, L. E., Mann, F. D., Briley, D. A., Church, J. A., Harden, K. P., Tucker-Drob, E. M. (2016). Strong Genetic Overlap Between Executive Functions and Intelligence. Journal of Experimental Psychology: General, 145, 11411159.

Epstein, S. (1973). The self-concept revisited. Or a theory of a theory. The American Psychologist, 28(5), 404-416.

Epstein, S., Lipson, A., Holstein, C., \& Huh, E. (1992). Irrational reactions to negative outcomes: evidence for two conceptual systems. Journal of Personality and Social Psychology, 62(2), 328-339.

Fayard, J. V., Roberts, B. W., Robins, R. W., \& Watson, D. 
(2012). Uncovering the affective core of conscientiousness: The role of self-conscious emotions. Journal of Personality, 80(1), 1-32.

Fleeson, W. (2001). Toward a structure- and processintegrated view of personality: Traits as density distributions of states. Journal of Personality and Social Psychology, 80(6), 1011-1027.

Friese, M., Loschelder, D. D. D., Gieseler, K., Frankenbach, J., \& Inzlicht, M. (2019). Is Ego Depletion Real? An Analysis of Arguments. Personality and Social Psychology Review, 23(2), 107-131.

Fujita, K. (2011). On conceptualizing self-control as more than the effortful inhibition of impulses. Personality and Social Psychology Review, 15(4), 352-366.

Fujita, K., Trope, Y., Liberman, N., \& Levin-Sagi, M. (2006). Construal levels and self-control. Journal of Personality and Social Psychology, 90(3), 351-367.

Galla, B. M., \& Duckworth, A. L. (2015). More than resisting temptation: Beneficial habits mediate the relationship between self-control and positive life outcomes. Journal of Personality and Social Psychology, 109(3), 508-525.

Gillebaart, M. (2018). The "operational" definition of selfcontrol. Frontiers in Psychology, 9(JUL), 1-5.

Gillebaart, M., \& de Ridder, D. T. D. (2015). Effortless selfcontrol: A novel perspective on response conflict strategies in trait self-control. Social and Personality Psychology Compass, 9(2), 88-99.

Gillebaart, M., \& De Ridder, D. T. D. (2015). Effortless slefcontrol: a novel perspective on response conflict strategies in trait self-control. Social and Personality Psychology Compass, 9, 88-99.

Gollwitzer, P. M. (1999). Implementation Intentions: Strong effects of simple plans. American Psychologist, 54(7), 493-503.

Gollwitzer, P. M., \& Sheeran, P. (2006). Implementation Intentions and Goal Achievement: A Meta-analysis of Effects and Processes. Advances in Experimental Social Psychology.

Gottfredson, L. S. (1997). Mainstream science on intelligence: An editorial with 52 signatories, history, and bibliography. Intelligence, 24(1), 13-23.

Gray, J. A., \& McNaughton, N. (2000). The neuropsychology of anxiety: An enquiry into the functions of the septohippocampal system. Oxford, England: Oxford University Press.

Gross, J. J. (2015). Emotion Regulation: Current Status and Future Prospects. Psychological Inquiry, 26(1), 1-26.

Hagger, M. S., Chatzisarantis, N.L.D., Alberts, H., Anggono, C.O., Batailler, C., Birt, A., Brand, R., Brandt, M.J., Brewer, G., Bruyneel, S., Calvillo, D.P., Campbell, W.K., Cannon, P.R., Carlucci, M., Carruth, N., Cheung, T., Crowell, A., De Ridder, D.T.D., Dewitte, S., Elson, M., ... Zweinenberg, M. (2016). A multi-lab pre-registered replication of the ego-depletion effect. Perspectives on Psychological Science, 11, 546-573.

Hagger, M. S., Wood, C., Stiff, C., \& Chatzisarantis, N. L.
D. (2010). Ego depletion and the strength model of selfcontrol: a meta-analysis. Psychological Bulletin, 136(4), 495-525.

Hare, T. a, Camerer, C. F., \& Rangel, A. (2009). Self-control in decision-making involves modulation of the vmPFC valuation system. Science (New York, N.Y.), 324(5927), 646-648.

Heatherton, T. F., \& Wagner, D. D. (2011). Cognitive neuroscience of self-regulation failure. Trends in Cognitive Sciences, 15(3), 132-139. h

Hennecke, M., Czikmantori, T., \& Brandstätter, V. (2019). Doing Despite Disliking: Self-regulatory Strategies in Everyday Aversive Activities. European Journal of Personality, 33(1), 104-128.

Higgins, E. T., Shah, J., \& Friedman, R. (1997). Emotional Responses to Goal Attainment: Strength of Regulatory Focus as Moderator. Journal of Personality and Social Psychology, 72(3), 515-525.

Hill, P. L., \& Jackson, J. J. (2016). The invest-and-accrue model of conscientiousness. Review of General Psychology, 20(2), 141-154.

Hill, P. L., Nickel, L. B., \& Roberts, B. W. (2014). Are You in a Healthy Relationship? Linking Conscientiousness to Health via Implementing and Immunizing Behaviors. Journal of Personality, 82(6), 485-492.

Hockey, G. R. J. (2013). The Psychology of Fatigue. Cambridge, UK: Cambridge Univerity Press.

Hofmann, W., Baumeister, R. F., Förster, G., \& Vohs, K. D. (2012). Everyday temptations: An experience sampling study of desire, conflict, and self-control. Journal of Personality and Social Psychology, 102(6), 1318-1335.

Hofmann, W., Friese, M., \& Strack, F. (2009). Impulse and Self-Control From a Dual-Systems Perspective. Perspectives on Psychological Science, 4(2), 162-176.

Hofmann, W., \& Kotabe, H. (2012). A General Model of Preventive and Interventive Self-Control. Social and Personality Psychology Compass, 6(10), 707-722.

Hofmann, W., Kotabe, H., \& Luhmann, M. (2013). The spoiled pleasure of giving in to temptation. Motivation and Emotion, 37(4), 733-742.

Hofmann, W., Schmeichel, B. J., \& Baddeley, A. D. (2012). Executive functions and self-regulation. Trends in Cognitive Sciences, 16(3), 174-180.

Holroyd, C. B., \& Coles, M. G. H. (2002). The neural basis of human error processing: Reinforcement learning, dopamine, and the error-related negativity. Psychological Review, 109(4), 679-709.

Inzlicht, M., Bartholow, B. D., \& Hirsh, J. B. (2015). Emotional foundations of cognitive control. Trends in Cognitive Sciences, 19(3), 126-132.

Inzlicht, M., \& Berkman, E. T. (2015). Six Questions for the Resource Model of Control ( and Some Answers ), 10, 114.

Inzlicht, M., \& Friese, M. (2019). The Past, Present, and Future of Ego Depletion, Social Psychology, 50, 370-378. Inzlicht, M., Legault, L., \& Teper, R. (2014). Exploring the mechanisms of self-control improvement. Current 
Directions in Psychological Science, 23(4), 302-307.

Inzlicht, M., \& Schmeichel, B. J. (2012). What Is Ego Depletion? Toward a Mechanistic Revision of the Resource Model of Self-Control. Perspectives on Psychological Science, 7(5), 450-463.

Inzlicht, M., Schmeichel, B. J., \& Macrae, C. N. (2014). Why self-control seems (but may not be) limited. Trends in Cognitive Sciences, 18(3), 127-133.

Inzlicht, M., Shenhav, A., \& Olivola, C. Y. (2018). The Effort Paradox: Effort Is Both Costly and Valued. Trends in Cognitive Sciences, 22(4), 337-349.

Jewsbury, P. A., Bowden, S. C., \& Strauss, M. E. (2016). Integrating the switching, inhibition, and updating model of executive function with the cattell-horn-carroll model. Journal of Experimental Psychology: General, 145(2), 220-245.

Kahneman, D. (2011). Thinking, fast and slow. Toronto, Ontario: Anchor Canada.

Kool, W., \& Botvinick, M. M. (2014). A labor/leisure tradeoff in cognitive control. Journal of Experimental Psychology. General, 143(1), 131-141.

Kool, W., \& Botvinick, M. M. (2018). Mental labour. Nature Human Behaviour, 2, 899-908.

Kool, W., McGuire, J. T., Rosen, Z. B., \& Botvinick, M. M. (2010). Decision making and the avoidance of cognitive demand. Journal of Experimental Psychology. General, 139(4), 665-682.

Kool, W., Shenhav, A., \& Botvinick, M. M. (2017). Cognitive control as cost-benefit decision making. In T. Egner (Ed.), Wiley Handbook of Cognitive Control (pp. 167-189). Chichester, West Sussex, UK: John Wiley \& Sons.

Köpetz, C., Faber, T., Fishbach, A., \& Kruglanski, A. W. (2011). The Multifinality Constraints Effect: How Goal Multiplicity Narrows the Means Set to a Focal End. Journal of Personality and Social Psychology.

Kronke, K.-M., Wolff, M., Mohr, H., Kraplin, A., Smolka, M., Buhringer, G., \& Goschke, T. (in press). Predicting Real-Life Self-Control by Brain Activity Encoding the Value of Anticipated Future Outcomes. Psychological Science.

Kruglanski, A. W., Shah, J. Y., Fishbach, A., Friedman, R., Woo Young Chun, \& Sleeth-Keppler, D. (2002). A theory of goal systems. Advances in Experimental Social Psychology, 34, 331-378.

Kurzban, R. (2016). The Sense of Effort. Current Opinion in Psychology, 7, 67-70.

Kurzban, R., Duckworth, A. L., Kable, J. W., \& Myers, J. (2013). An opportunity cost model of subjective effort and task performance. The Behavioral and Brain Sciences, 36(6), 661-679.

Lin, H., Saunders, B., Friese, M., Evans, N. J., \& Inzlicht, M. (in press). Strong effort manipulations reduce response caution: A preregistered reinvention of the ego depletion paradigm. Psychological Science.

Lin, H., Saunders, B., Hutcherson, C. A., \& Inzlicht, M. (2017). Midfrontal theta and pupil dilation parametrically track subjective conflict (but also surprise) during intertemporal choice. BioRxiv, 172, 838-852.

Locke, E. a., \& Latham, G. P. (2006). New Directions in Goal-Setting Theory. Current Directions in Psychological Science, 15(5), 265-268.

Lopez, R. B., Chen, P. H. A., Huckins, J. F., Hofmann, W., Kelley, W. M., \& Heatherton, T. F. (2017). A balance of activity in brain control and reward systems predicts selfregulatory outcomes. Social Cognitive and Affective Neuroscience, 12(5), 832-838.

Lopez, R. B., Hofmann, W., Wagner, D. D., Kelley, W. M., \& Heatherton, T. F. (2014). Neural Predictors of Giving in to Temptation in Daily Life. Psychological Science, 25, 1337-1344.

Ludwig, R. M., Srivastava, S., \& Berkman, E. T. (2019). Predicting Exercise With a Personality Facet: Planfulness and Goal Achievement. Psychological Science, 30(10), $1510-1521$

Ludwig, R. M., Srivastava, S., \& Berkman, E. T. (2018). Planfulness: A Process-Focused Construct of Individual Differences in Goal Achievement. Collabra: Psychology, 4(1), 1-18.

Mackworth, N. H. (1948). The Breakdown of Vigilance during Prolonged Visual Search. Quarterly Journal of Experimental Psychology, 1(1), 6-21.

Metcalfe, J., \& Mischel, W. (1999). A hot/cool-system analysis of delay of gratification: dynamics of willpower. Psychological Review, 106, 3-19.

Milyavskaya, M., Berkman, E. T., \& De Ridder, D. T. D. (2019). The many faces of self-control: Tacit assumptions and recommendations to deal with them. Motivation Science, 5(1), 79-85.

Milyavskaya, M., \& Inzlicht, M. (2017). What's So Great About Self-Control? Examining the Importance of Effortful Self-Control and Temptation in Predicting RealLife Depletion and Goal Attainment. Social Psychological and Personality Science, 8(6), 603-611.

Milyavskaya, M., Inzlicht, M., Hope, N., \& Koestner, R. (2015). Saying "No" to Temptation: Want-to Motivation Improves Self-Regulation by Reducing Temptation Rather Than by Increasing Self-Control. Journal of Personality and Social Psychology, 109(4), 677-693.

Milyavskaya, M., Inzlicht, M., Johnson, T., \& Larson, M. J. (2019). Reward sensitivity following boredom and cognitive effort: A high-powered neurophysiological investigation. Neuropsychologia, 123(March 2018), 159168.

Mischel, W., Ebbesen, E. B., \& Raskoff Zeiss, A. (1972). Cognitive and attentional mechanisms in delay of gratification. Journal of Personality and Social Psychology, 204-218.

Mischel, W., Shoda, Y., \& Rodriguez, M. (1989). Delay of gratification in children. Science, 933-938.

Miyake, A., \& Friedman, N. P. (2012). The Nature and Organization of Individual Differences in Executive Functions: Four General Conclusions. Current Directions in Psychological Science, 21(1), 8-14. 
Miyake, A., Friedman, N. P., Emerson, M. J., Witzki, A. H., Howerter, A., \& Wager, T. D. (2000). The unity and diversity of executive functions and their contributions to complex "Frontal Lobe" tasks: a latent variable analysis. Cognitive Psychology, 41(1), 49-100.

Moffitt, T. E., Arseneault, L., Belsky, D., Dickson, N., Hancox, R. J., Harrington, H., ... Caspi, A. (2011). A gradient of childhood self-control predicts health, wealth, and public safety. Proceedings of the National Academy of Sciences of the United States of America, 108(7), 26932698.

Moutafi, J., Furnham, A., \& Paltiel, L. (2004). Why is Conscientiousness negatively correlated with intelligence? Personality and Individual Differences, 37(5), 1013-1022.

Neal, A., Ballard, T., \& Vancouver, J. B. (2017). Dynamic Self-Regulation and Multiple-Goal Pursuit. Annual Review of Organizational Psychology and Organizational Behavior, 4, 401-423.

Oettingen, G., Mayer, D., Timur Sevincer, A., Stephens, E. J., Pak, H., \& Hagenah, M. (2009). Mental contrasting and goal commitment: the mediating role of energization. Personality \& Social Psychology Bulletin, 35, 608-622.

Proulx, T., Inzlicht, M., \& Harmon-Jones, E. (2012). Understanding all inconsistency compensation as a palliative response to violated expectations. Trends in Cognitive Sciences, 16(5), 285-291.

Randles, D., Harlow, I., \& Inzlicht, M. (2017). A preregistered naturalistic observation of within domain mental fatigue and domain-general depletion of self-control. Plos One, 12(9), e0182980.

Roberts, B. W. (2018). A Revised Sociogenomic Model of Personality Traits. In Journal of Personality (Vol. 86, pp. 23-35). Blackwell Publishing Ltd. h

Roberts, B. W., Lejuez, C., Krueger, R. F., Richards, J. M., \& Hill, P. L. (2014). What is conscientiousness and how can it be assessed? Developmental Psychology, 50(5), 1315-1330.

Rothbart, M. K., Ellis, L. K., Rueda, M. R., \& Posner, M. I. (2003). Developing Mechanisms of Temperamental Effortful Control. Journal of Personality, 71, 1113-1143.

Ryan, R. M., \& Deci, E. L. (2000). Self-determination theory and the facilitation of intrinsic motivation, social development, and well-being. The American Psychologist, $55(1), 68-78$.

Saunders, B., Lin, H., Milyavskaya, M., \& Inzlicht, M. (2016). The emotive nature of conflict monitoring in the medial prefrontal cortex. International Journal of Psychophysiology, 119, 31-40.

Saunders, B., Milyavskaya, M., Etz, A., Randles, D., \& Inzlicht, M. (2018). Reported self-control is not meaningfully associated with inhibition-related executive function: A Bayesian analysis. Collabra: Psychlogy, 4, 39.

Saunders, B., Milyavskaya, M., \& Inzlicht, M. (2015). What does cognitive control feel like? Effective and ineffective cognitive control is associated with divergent phenomenology. Psychophysiology, 52(9), 1205-1217.

Shah, J. Y., Friedman, R., \& Kruglanski, A. W. (2002).
Forgetting all else: On the antecedents and consequences of goal shielding. Journal of Personality and Social Psychology, 83(6), 1261-1280.

Shenhav, A. (2017, July 3). The Perils of Losing Control: Why Self-Control Is Not Just Another Value-Based Decision. Psychological Inquiry. Routledge.

Shenhav, A., Botvinick, M. M., \& Cohen, J. D. (2013). The Expected Value of Control: An Integrative Theory of Anterior Cingulate Cortex Function. Neuron, 79, 217-240.

Shenhav, A., \& Buckner, R. L. (2014). Neural correlates of dueling affective reactions to win-win choices. Proceedings of the National Academy of Sciences, 111(30), 10978-10983.

Shenhav, A., Cohen, J. D., \& Botvinick, M. M. (2016). Dorsal anterior cingulate cortex and the value of control. Nature Neuroscience, 19(10), 1286-1291.

Spunt, R. P., Lieberman, M. D., Cohen, J. R., \& Eisenberger, N. I. (2012). The phenomenology of error processing: the dorsal ACC response to stop-signal errors tracks reports of negative affect. Journal of Cognitive Neuroscience, 24(8), 1753-1765.

Sullivan, N., Hutcherson, C., Harris, a., \& Rangel, a. (2014). Dietary Self-Control Is Related to the Speed With Which Attributes of Healthfulness and Tastiness Are Processed. Psychological Science.

Tangney, J. P., Baumeister, R. F., \& Boone, A. L. (2004). High Self-Control Predicts Good Adjustment, Less Pathology, Better Grades, and Interpersonal Success. Journal of Personality, 72(April 2004), 271-324.

Thaler, R. H., \& Shefrin, H. M. (1981). An Economic Theory of Self-Control. Journal of Political Economy, 89(2), 392406.

Thorndike, E. L. (1900). Mental fatigue. Psychological Review, 7, 547-579.

Tracy, J. L., \& Robins, R. W. (2004). Putting the self into self-conscious emotions: A theoretical model. Psychological Inquiry. Routledge.

Tusche, A., \& Hutcherson, C. A. (2018). Cognitive regulation alters social and dietary choice by changing attribute representations in domain-general and domainspecific brain circuits. ELife, 7 .

Vassena, E., Holroyd, C. B., \& Alexander, W. H. (2017). Computational Models of Anterior Cingulate Cortex : At the Crossroads between Prediction and Effort. Frontiers in Neuroscience, 11, 316.

Vohs, K. D., \& Baumeister, R. F. (2004). Understanding selfregulation: An introduction. In R. F. Baumeister \& K. D. Vohs (Eds.), Handbook of Self-Regulation: Research, Theory, and Applications (pp. 1-9). New York, NY: Guilford Press. Retrieved from

Vosgerau, J., Scopelliti, I., \& Huh, Y. E. (2020). Exerting Self-Control $\neq$ Sacrificing Pleasure. Journal of Consumer Psychology, 30(1), 181-200.

Watts, T. W., Duncan, G. J., \& Quan, H. (2018). Revisiting the Marshmallow Test: A Conceptual Replication Investigating Links Between Early Delay of Gratification and Later Outcomes. Psychological Science, 29, 1159- 
1177.

Werner, K. M., \& Milyavskaya, M. (2018). Motivation and self-regulation: The role of want-to motivation in the processes underlying self-regulation and self-control. Social and Personality Psychology Compass, e12425.

Westbrook, A., Kester, D., \& Braver, T. S. (2013). What is the subjective cost of cognitive effort? Load, trait, and aging effects revealed by economic preference. PloS One, 8(7), e68210.

Whiteside, S. P., \& Lynam, D. R. (2001). The five factor model and impulsivity: Using a structural model of personality to understand impulsivity. Personality and Individual Differences, 30(4), 669-689.

Wiener, N. (1948). Cybernetics or Control and Communication in the Animal and the Machine. Oxford, England: John Wiley.

Wilkowski, B. M., \& Ferguson, E. L. (2016). The steps that can take us miles: Examining the short-term dynamics of long-term daily goal pursuit. Journal of Experimental
Psychology: General, 145(4), 516-529.

Wilkowski, B. M., Ferguson, E. L., Williamson, L. Z., \& Lappi, S. K. (2018). (How) Does Initial Self-Control Undermine Later Self-Control in Daily Life? Personality and Social Psychology Bulletin, 44(9), 1315-1329.

Wrosch, C., Scheier, M. F., Miller, G. E., Schulz, R., \& Carver, C. S. (2003). Adaptive Self-Regulation of Unattainable Goals: Goal Disengagement, Goal Reengagement, and Subjective Well-Being. Personality and Social Psychology Bulletin, 29, 1494-1508.

Zajenkowski, M., \& Stolarski, M. (2015). Is conscientiousness positively or negatively related to intelligence? Insights from the national level. Learning and Individual Differences, 43, 199-203.

This pre-print was designed using the following template: Wiernik, B. M. (2019, October 11). Preprint templates. https://doi.org/10.17605/OSF.IO/HSV6A 